\title{
A STATISTICAL STUDY OF COAL-MINING ACCIDENTS
}

\author{
BY \\ F. D. K. LIDDELL and JOAN MAY \\ From the National Coal Board, Hobart House, Grosvenor Place, London
}

(RECEIVED FOR PUBLICATION MARCH 6, 1958)

Statistics of accidents in British coal-mines have been collected in one form or another since 1873 (Ministry of Power, 1957). From those early days there has been a steady decline in the numbers of fatalities but even now more than $\mathbf{3 0 0}$ men a year are killed in mining accidents. About a million and a half injuries, varying from the trivial to the fatal, are reported in a year and coal-miners, who form only about a twentieth of the insured male population of Great Britain, account for nearly half of all industrial injuries attracting benefit.

Because of, on the one hand, the requirements of the Mines Inspectorate of the Ministry of Power, and, on the other, arrangements for compensation, casualties* in the industry are classified into the following four categories:

(a) Fatal casualty.

(b) Other "reportable" casualty: a report must be made to the Mines Inspectorate of any case of " serious personal injury" (such as a major fracture) and of every "dangerous occurrence ". $\dagger$

(c) Other compensable casualty: an injury which causes absence from work for more than three days and which is therefore compensable under the National Insurance (Industrial Injuries) Act.

(d) Non-compensable casualty, i.e., any casualty not included in the three categories above.

Although the great majority of casualties are in category $(d)$, the compensable casualties, i.e., those in categories $(a)$ and $(c)$ together with most of those in (b), amount at present to over 200,000 a year. For the years 1945 to 1949 inclusive, certain information about these casualties was reported to the

"In this paper " casualty " refers to a man injured in an " accident". An accident may cause more than one casualty, and a casualty may have more than one injury.

tSee Ministry of Power (1957) for a definition of "reportable". accidents. (New regulations have since changed this definition.)
Ministry of Power where a card was punched for each casualty. It was natural to assume that this material, consisting of over 900,000 cards, would be a reasonable source of data for statistical research. The material (data A) was, therefore, borrowed by the National Coal Board and the work described below was carried out on it. Work was also done by the technical section of the Board's central Statistics Branch on more detailed and more up-todate material (data B) relating to 14 collieries onlyless than $2 \%$ of those in the Board. The third source of material (data C) was available in the shape of colliery accident rates and other colliery statistics. These data are described in detail below.

Despite the vast amount of data available, the conclusions were mainly negative. This was largely because standards of recording and habits of reporting appeared to differ appreciably and because the background information necessary for detailed work was not available. There were, however, a number of positive findings which are discussed in this paper.

\section{The Data}

The three bodies of data studied are described below:

Data A.-For each compensable casualty occurring in the five years 1945 to 1949 , one 45 -column Powers-Samas card had been punched. The data, obtained from a statutory return, contained information about the man involved, the time, place, and cause of accident, the resulting injury, and the length of absence which followed.

Data B.-For each compensable casualty occurring during 1953 at eight collieries in one area, $X$, and at six collieries in another area, $Y$, in a different division* one 80-column Hollerith card had been punched. The data were obtained from an accident

*There are 900 collieries in the N.C.B. grouped into 51 areas which are further grouped into nine divisions. 
report form which had been coded at divisional level. The information punched was similar to that of data A, but more detailed.

Data C.-One punched card for each colliery contained two accident rates for both 1953 and 1954: underground (number of compensable underground casualties per 100,000 manshifts worked underground) and surface (number of compensable surface casualties per 100,000 manshifts worked on the surface). A variety of descriptive information about the colliery is also available on the card, which forms part of the "colliery profile"."

Classification of Casualties.-All the data described above relate to compensable casualties, including, at the extremes, fatalities, and men suffering from minor injuries, but excluding injuries not causing at least four days' absence. The distinction between the categories of casualty described above is, of course, largely arbitrary and it is instructive to compare the rates of compensable casualties with those for other categories.

If habits of reporting and standards of recording did not vary, it would be expected that a group of collieries which are "safe" would have a low rate for each category of injury, whereas collieries which are " dangerous" would have high rates.

Fatal accidents are too rare to allow of an examination for individual pits over any reasonable period of time, but it is possible to study figures for N.C.B. divisions. On the hypothesis that the rates of the various categories of casualty each reflect the degree of safety in a division, we would expect a high correlation between each pair of rates. In fact, such correlations are not found except between the rates of fatalities and of other reportable casualties, and here the correlation coefficient is $+\mathbf{0} \cdot \mathbf{8}$. In no other case is there any trace of the positive association that our hypothesis would lead us to expect.

Confirmation can be found in an examination of area rates. There is no correlation between the rates of fatal and non-fatal (compensable) accidents in 1954 , but since there are few fatal accidents in any area in one year the rates are rather unreliable. However, there is no trace of correlation between area rates of all reportable casualties (categories $(a)$ and (b) combined) and rates of other compensable injuries.

Further evidence is found in Fig. 1, where fatal, reportable, and compensable rates are compared from 1927 to 1957 . Obviously there is less possibility of anomalies in recording fatal and reportable injuries than with other categories, and it can be

\footnotetext{
*See Liddell (1955) for a description of the " colliery profile" for 1953.
}

seen that these two rates, which might be expected to reflect the true danger of coal-mining as an occupation, have been decreasing steadily, while the compensable accident rate rose steeply in 1948, the year in which the National Insurance (Industrial Injuries) Act came into force.

Since the two rates found to be associated are those which are least open to question it would appear that the hypothesis being examined is untenable. In other words the compensable accident rate does not appear to be a true reflection of the degree of safety, but depends on such factors as habits of reporting.

Differences in Recording of Data.-That there are differences in recording is not surprising. There is one form of report available throughout the industry for accidents which are not statutorily reportable to H.M. inspectors of mines, but it is not used in every colliery and where it is used it is completed under diverse local instructions by men with varying responsibility.

It should be borne in mind that none of the information had been collected for research purposes, and discrepancies and shortcomings, which suggested that too detailed an examination could not be justified, were inevitable. For example, the percentage of answers in the category " cause of accident" that were coded as " unclassified" in data B was in some collieries over $90 \%$ and for surface workers was never lower than $40 \%$. There were important differences between collieries in their use of the coding " unclassified " which were clearly due to different habits of recording. Furthermore, discrepancies such as the recording of the place of an accident as "elsewhere underground" when its recorded cause is one specific to the coalface, were found frequently enough to reflect on the value of the material. In addition, large and consistent differences were found in data $B$ between the two areas: the pits in Area $X$ had higher accident rates than those in Area $Y$, but their absences were considerably shorter.

It was found in data $\mathbf{A}$ that collieries used two different methods of recording the length of absence; some collieries recorded absences consisting of a number of weeks plus anything up to six days but the majority recorded absences of a number of weeks and only up to five days. It appeared, too, that the day of start of absence and day of return to work might or might not be included in the absence; in some collieries only complete weeks of absence were recorded. Similarly, in data B absences of six, 13, 20, etc., days were never obtained. There seemed to be a definite tendency for men to be recorded as returning to work after having had 
CASUALTIES PER THOUSAND EMPLOYED

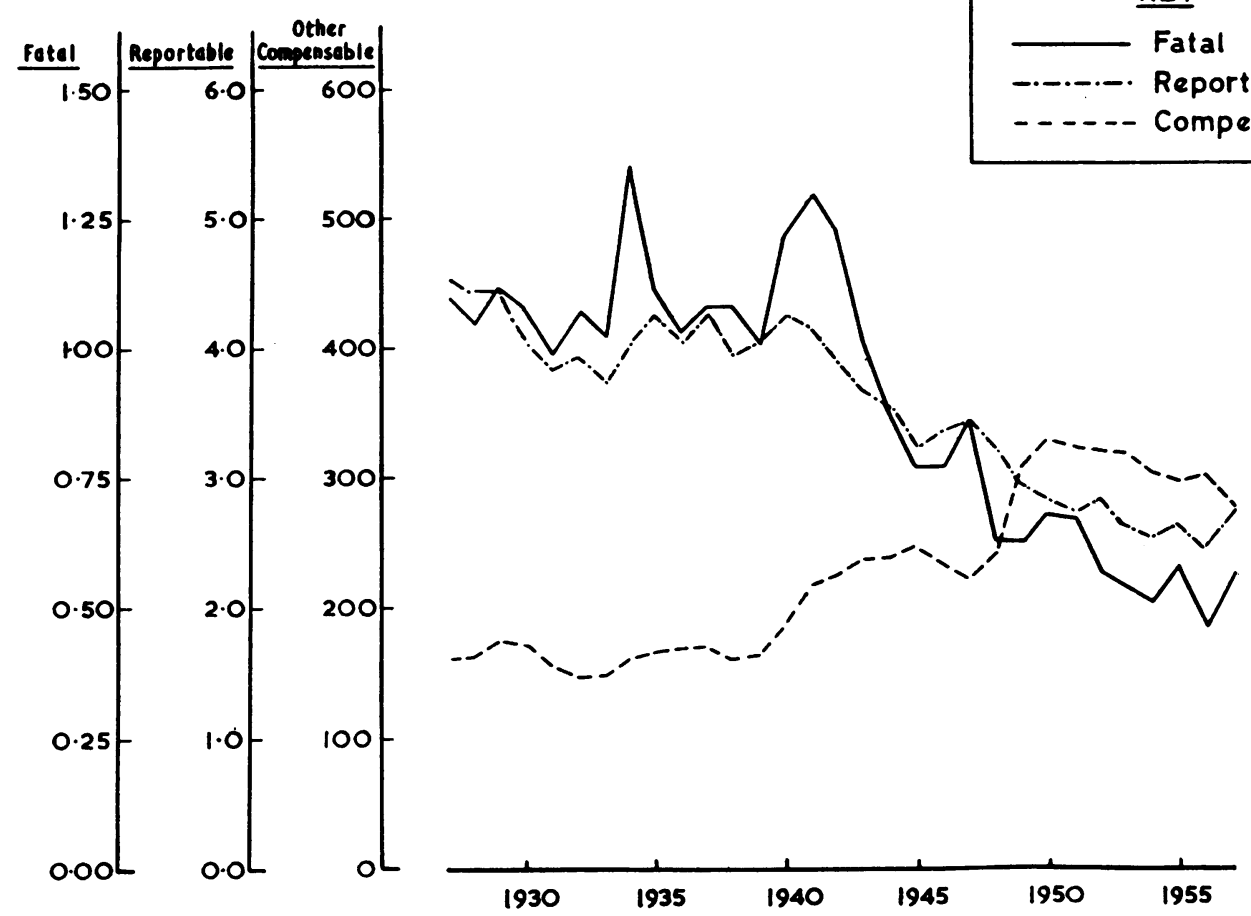

Fig. 1.-Accident rates in British coal-mines, 1927-57.

absences of complete weeks irrespective of the day of the week on which the accident had occurred. For these reasons the data contained extremely irregular distributions of absence.

It was possible to obtain some details of manpower and manshifts to give denominators and enable us to compute accident rates for certain groups, for both data A and data B, but there were difficulties here also. In particular the breakdown of the population by age and occupation simultaneously was not available.

Finally, it must be remembered that not only do mining methods and environmental conditions vary widely from colliery to colliery (and indeed in many cases within the colliery from coalface to coalface) but also that similar occupations are defined differently in different pits. Hence strictly comparable conditions are hard to find and casualty rates for a colliery reflect a whole complex of situations.

\section{Analysis of Data}

Despite these drawbacks, it was felt that, as this material was the first of its kind available in the coal industry, it was worth detailed examination. A number of results which appear reliable and in- structive were obtained and are discussed below.

Methods.-Wherever possible, both incidence and length of absence following an accident were examined, using the following measures:

(a) "Casualty rate", taken as the number of casualties occurring in a particular class of worker divided by the number of men in this class. (The casualties refer to a year's experience but the numbers of men are those employed in a particular week in the year. Thus the numerator and denominator of the rate are not strictly comparable.)

(b) " Accident rate", taken as the number of casualties divided by the number of manshifts worked over the year.

(c) "Length of absence", taken as the median length. All those absences which were " not recovered"* were counted as greater than the median.

The use of the median length of absence requires justification. This measure is not unreliable when based on large numbers of casualties: its particular virtue is that it takes reasonable account of the " not recovered" cases, and is not unduly affected by occasional very long absences. However, as already explained, the distribu-

*Under " period of disablement " collieries were instructed to enter " not recovered" if the person had not returned to work when the statutory return was sent to H.M. Inspector of Mines, which would have been by January 21 of the following year. 
tions of length of absence are very irregular, and so the median should be regarded with caution.

Because of the nature of the distribution of lengths of absence, the median is always considerably lower than the arithmetical average. A study carried out on the figures for 1951 which traced back the length of absences in the vast majority of cases (thus reducing the " not recovered " class to a minimum) gave a mean length of absence of 27 working days. This compares with a median figure of some 18 days estimated in our present study for 1949, using data A.

Since data A refer to nearly a million casualties in all, it was always necessary to work with samples of collieries. A separate sample was taken for each study; a description of each sample is given in the appropriate section.

Throughout these studies it was found that accident experience differed significantly between the three main places of work: coalface, elsewhere underground, and surface. Coalface workers had the highest rate, then workers elsewhere underground; surface workers had the lowest rate. This pattern was consistent from pit to pit and from year to year. It was clear that the three places had to be kept separate in all further studies.

\section{Results}

Accident Experience and Age.-Data A and B were used to study this factor. From data A, samples of 10 collieries were taken for each of the years 1948 and 1949, these years being both convenient and the latest for which data were available. No colliery was included in both samples. No collieries employing fewer than 1,000 men were included, because the numbers of men and of casualties in the subclasses examined would be too small to provide a reasonable basis for analysis. Further, the manpower returns for 1949 referring to one division were not available, and that division was therefore excluded from the sample for that year.

The results from the two sources are remarkably similar, despite the differences in coverage.

In Table 1, the casualty rates, based on numbers of men employed in age groups, are given for data $\mathrm{A}$. There is a considerable increase in the rates over the two years covered. The provisions of the National Insurance (Industrial Injuries) Act and of the Supplementary Scheme for Colliery Workers came into force in July, 1948, and may have had something to do with this effect.

The results for data $B$ were similar and such differences as there were are probably accounted for by the differences in geographical coverage of the two bodies of data, even although data B were for 1953.

There was an overall tendency for the casualty rate to decrease with age. This might be due to such factors as greater carelessness in younger men, or to a tendency for younger men to report injuries
TABLE 1

CASUALTY RATES BY AGE AND PLACE OF WORK: DATA A (Number of casualties per man employed)

\begin{tabular}{l|c|c|c|c}
\hline \multirow{2}{*}{ Age } & & \multicolumn{3}{|c}{ Place of Work } \\
\cline { 3 - 5 } & Year & Coalface & $\begin{array}{c}\text { Elsewhere } \\
\text { Underground }\end{array}$ & Surface \\
\hline Under 21 & 1948 & 0.73 & 0.28 & 0.17 \\
21 to 30 & 1949 & 0.74 & 0.46 & 0.25 \\
& 1948 & 0.35 & 0.24 & 0.10 \\
31 to 50 & 1949 & 0.53 & 0.37 & 0.21 \\
& 1948 & 0.39 & 0.20 & 0.09 \\
51 and over & 1949 & 0.57 & 0.26 & 0.15 \\
& 1948 & 0.46 & 0.17 & 0.08 \\
\hline Total & 1949 & 0.47 & 0.18 & 0.10 \\
& 1948 & 0.39 & 0.21 & 0.10 \\
\hline
\end{tabular}

more freely, or for them to be given the most dangerous work. Within each age group it was clear that coalface workers had the highest casualty rates and surface workers the lowest.

There was an overall tendency for the length of absence to increase with age, except for men under 21. Within each age group there was the same pattern of length of absence as for all men, namely, coalface workers had the shortest absences of their age group. The figures for data $B$ are shown in Table 2. Those for data $\mathbf{A}$ are again in close agreement, although they are less reliable on account of a large proportion of " not recovered" casualties.

TABLE 2

LENGTH OF ABSENCE BY AGE AND PLACE OF WORK: (Median length of absence in days)

\begin{tabular}{|c|c|c|c|}
\hline \multirow[b]{2}{*}{ Age } & \multicolumn{3}{|c|}{ Place of Work } \\
\hline & Coalface & $\begin{array}{c}\text { Elsewhere } \\
\text { Underground }\end{array}$ & Surface \\
\hline $\begin{array}{l}\text { Under } 21 \\
21 \text { to } 25 \\
26 \text { to } 30 \\
31 \text { to } 40 \\
41 \text { to } 50 \\
51 \text { to } 55 \\
56 \text { and over }\end{array}$ & $\begin{array}{l}15 \\
15 \\
15 \\
16 \\
19 \\
22 \\
24\end{array}$ & $\begin{array}{l}18 \\
17 \\
18 \\
19 \\
24 \\
23 \\
26\end{array}$ & $\begin{array}{l}17 \\
15 \\
18 \\
18 \\
21 \\
23 \\
28\end{array}$ \\
\hline Total .. & 17 & 21 & 19 \\
\hline
\end{tabular}

The fact that the older men experienced longer absences wherever they were working might have been because they tended to incur a disproportionate number of serious injuries. In order to examine this possibility it was necessary to group the casualties by age and by severity of injury simultaneously. The groupings of injuries, which were only slightly different for the two sets of data, are given overleaf.

Using data A for 1949, Table 3 shows casualty rates by age and type of injury. It is clear that there is very little difference between the age groups in the incidence of serious injuries but that for the less severe injuries there is a steady decrease in the rates 


\begin{tabular}{|c|c|c|}
\hline Type & Data A & Data B \\
\hline 1 (Slight) & $\begin{array}{l}\text { Bruises foreign bodies, } \\
\text { Cuts, forains }\end{array}$ & $\begin{array}{l}\text { Bruises } \\
\text { Cuts, foreign bodies, } \\
\text { lacerations, penetrating } \\
\text { wounds }\end{array}$ \\
\hline 3 & Burns, rupture, strains & $\begin{array}{l}\text { Burns, rupture, strains, } \\
\text { sprains }\end{array}$ \\
\hline 4 (Serious) & $\begin{array}{l}\text { Crushing, fractures, dis- } \\
\text { locations, concussion, } \\
\text { amputations, asphyxi- } \\
\text { ation, electric shock, } \\
\text { c a r b o n monoxide } \\
\text { poisoning }\end{array}$ & $\begin{array}{l}\text { Crushing, fractures, dis- } \\
\text { locations, concussion, } \\
\text { amputations, asphyxi- } \\
\text { ation, electric shock, } \\
\text { c a r b o n monoxide } \\
\text { poisoning }\end{array}$ \\
\hline
\end{tabular}

TABLE 3

CASUALTY RATES BY AGE AND TYPE OF INJURY: DATA A (1949)

(Number of casualties per man employed)

\begin{tabular}{l|l|l|l|l|l}
\hline \multirow{2}{*}{ Place of Work } & \multirow{2}{*}{ Type of Injury } & \multicolumn{4}{|c}{ Age } \\
\cline { 3 - 6 } & & $\begin{array}{l}\text { Under } \\
\text { Coalface }\end{array}$ & 21 to 30 & 31 to 50 & $\begin{array}{c}\text { S1 and } \\
\text { over }\end{array}$ \\
\hline & 1 (Slight) & 0.26 & 0.20 & 0.22 & 0.17 \\
& 2 & 0.30 & 0.19 & 0.18 & 0.16 \\
& 3 & 0.12 & 0.08 & 0.08 & 0.07 \\
& 4 (Serious) & 0.03 & 0.02 & 0.03 & 0.03 \\
\hline Elsewhere un- & 1 (Slight) & 0.18 & 0.13 & 0.09 & 0.07 \\
derground & 2 & 0.12 & 0.11 & 0.09 & 0.05 \\
& 3 & 0.04 & 0.05 & 0.05 & 0.03 \\
& 4 (Serious) & 0.03 & 0.02 & 0.02 & 0.02 \\
\hline Surface & 1 (Slight) & 0.08 & 0.07 & 0.04 & 0.03 \\
& 2 & 0.08 & 0.07 & 0.05 & 0.04 \\
& 3 & 0.04 & 0.03 & 0.04 & 0.02 \\
& 4 (Serious) & 0.01 & 0.01 & 0.02 & 0.01 \\
\hline
\end{tabular}

with increasing age. This pattern was not, however, consistent from pit to pit.

For data B, the pattern was not so clear cut, and a closer study was made which showed differences between the two areas. However, the rates of serious casualties were found to be comparatively consistent but the minor casualty rates were more diverse. This suggests that the differences in the patterns are due to varying willingness to report minor injuries rather than to differences in the true incidence of accidents.

Table 4 shows for data $A$ the length of absences

TABLE 4

LENGTH OF ABSENCE BY AGE AND TYPE OF INJURY: DATA A

(Median length of absence in days)

\begin{tabular}{l|l|c|c|c|c}
\hline \multirow{2}{*}{ Place of Work } & Type of Injury & \multicolumn{3}{|c}{ Age } \\
\cline { 3 - 6 } & $\begin{array}{c}\text { Under } \\
21\end{array}$ & 21 to 30 & 31 to 50 & $\begin{array}{c}51 \text { and } \\
\text { Over }\end{array}$ \\
\hline Coalface & 1 (Slight) & 18 & 14 & 16 & 22 \\
& 2 & 17 & 15 & 17 & 22 \\
& 3 & 23 & 14 & 18 & 21 \\
& 4 (Serious) & $74^{*}$ & 48 & 52 & 78 \\
\hline Elsewhere un- & 1 (Slight) & 15 & 14 & 18 & 24 \\
derground & 2 & 18 & 18 & 18 & 28 \\
& 3 & 23 & 15 & 23 & 30 \\
& 4 (Serious) & 126 & 53 & 66 & 120 \\
\hline Surface & 1 (Slight) & 15 & 14 & 16 & 24 \\
& 2 (S) & 16 & 14 & 22 & 21 \\
& 3 (Serious) & $78 *$ & 16 & 28 & 56 \\
& & 39 & 43 & 80 \\
\hline
\end{tabular}

*Based on small numbers according to age and type of injury. Except for the youngest group, the lengths of absences increase with age; but the most noticeable result is that the under-21s take as long as the over-50s to return to work after serious injury. Again it is of interest that the length of absence does not vary markedly from one place of work to another when account is taken of both age and severity of injury. This result is confirmed from data $B$.

Accident Experience and Occupation.-This section describes an examination of the casualty rates of men of different occupation within the mining industry. Although age is an important factor, as reported above, it had to be ignored here since distributions of the population by age and occupation simultaneously were not available.

For data A, a sample of 20 collieries was chosen from among the larger in the industry. It was impossible to include small collieries, for in the detailed breakdown of the figures required for this study, the number of casualties in such pits would be too small to allow of any reliable comparisons. As before, one division had to be excluded. The following occupational groups were used:

At the coalface ........... Getting, ripping, "others "

On the surface......... . Surface work

For data $B$ it was possible to obtain rates for three pieceworker categories only:

At the coalface ........... Coal-getters (hewers, fillers, composite workers); drillers and
cutter men; conveyor shifters

Casualty rates were computed from data $\mathrm{A}$ for each of these classes of occupation, and corresponding accident rates were obtained from data B. It was found that there was no single occupation, within the places of work, which consistently had high or low rates in most collieries, but there was wide variation from one pit to another in the rates for any particular occupation. A typical example is that of the eight collieries in Area $X$ which had accident rates for coal-getters varying from 0.96 casualties per 1,000 shifts to 3.97. It was thought that this variation might be due in part to different habits of reporting minor injuries in the different pits. Using the classification of type of injury discussed above, the minor injuries (Type 1) were removed from the study but even so among the more serious injuries wide variation was still found between pits for each of the occupations.

Accidents were then analysed by cause for each of the occupations separately and it was found that, as might be expected, men in different occupations suffered accidents due to different causes. However, the pattern varied from pit to pit. On the other hand, the type of injury suffered did not appear to 
vary from one occupation to another within each place of work; nor indeed did the type of injury vary clearly with the cause of the accident. This was found to be true for each place of work.

Finally, a study was made of the lengths of absence, and it was clear that, for similar types of injury, similar lengths of absence were taken, irrespective of what had caused the injury or whether the accident had taken place at the coalface or elsewhere underground. The lengths of absence for surface accidents could not be considered as the numbers of accidents in many categories were too small for their medians to be reliable. Table 5 illustrates the point for accidents occurring at the coalface.

TABLE 5

LENGTH OF ABSENCE BY CAUSE OF ACCIDENT AT COALFACE AND BY TYPE OF INJURY: DATA B (Median length of absence in days)

\begin{tabular}{l|c|c|c|c}
\hline \multirow{2}{*}{ Cause* } & \multicolumn{3}{|c}{ Type of Injury } \\
\cline { 2 - 5 } & $\begin{array}{l}1 \\
\text { (Slight) }\end{array}$ & 2 & 3 & $\begin{array}{c}4 \\
\text { (Serious) }\end{array}$ \\
\hline Falls of roof, etc., at coalface & 18 & 17 & 21 & 31 \\
Machinery, etc. & 16 & 16 & 16 & 42 \\
Stumbling, etc. & 17 & 16 & 17 & 24 \\
Falling objects & 18 & 15 & 15 & 40 \\
Other causes & 18 & 15 & 22 & 25 \\
\hline
\end{tabular}

*Certain causes were excluded, because the numbers were too small to give reliable medians.

Thus the apparent differences in lengths of absence taken by coalface workers compared with other workers have been explained by differences in age distributions at the three places of work, and by the different types of injury suffered there. Nevertheless, it is clear from Table 3 that coalface workers suffer substantially more serious injuries (Types 3 and 4) than other workers. This might at first sight appear to be a contradiction of the observation that coalface workers have shorter absences on the whole than other workers. However, the figures in Table 6, summarized from the same data as Table 3, show that this is due to the even greater preponderance of " slight" injuries among coalface workers.

Thus for coalface workers there are 6.8 times as

TABLE 6

CASUALTY RATES BY SEVERITY OF INJURY AND PLACE OF WORK: DATA A (1949)

(Number of casualties per man employed)

\begin{tabular}{l|c|c|c}
\hline \multirow{2}{*}{ Type of Injury } & \multicolumn{3}{|c}{ Place of Work } \\
\cline { 2 - 4 } & Coalface & $\begin{array}{c}\text { Elsewhere } \\
\text { Underground }\end{array}$ & Surface \\
\hline 1 (Slight) & 0.221 & 0.092 & 0.046 \\
4 (Serious) & 0.033 & 0.018 & 0.013 \\
\hline $\begin{array}{l}\text { Ratio of slight injuries to } \\
\text { serious injuries }\end{array}$ & 6.8 & 5.3 & 3.5 \\
\hline
\end{tabular}

many slight injuries as serious ones, whereas for surface workers this ratio is only $\mathbf{3 \cdot 5}$.

Size of Colliery and Method of Raising Coal.Using data C, a study was made of the effect of the size of colliery and the method of raising, by shaft or drift. Table 7 gives the mean accident rates and it can be seen that there is no clear indication that the underground accident rate increases with size of colliery, and it is obvious that surface rates are independent of the size of the colliery. The underground accident rate for drifts is lower than that for shafts, and it is possible that this accounts for some of the size effect found in other studies (Acton Society Trust, 1953; Paterson, 1956).

TABLE 7

ACCIDENT RATES BY SIZE OF COLLIERY AND METHOD OF RAISING: DATA C

(Number of casualties per hundred thousand manshifts worked)

\begin{tabular}{l|c|c|c}
\hline $\begin{array}{l}\text { Method } \\
\text { of } \\
\text { Raising }\end{array}$ & $\begin{array}{c}\text { Size of Colliery } \\
\text { (output in 1954) }\end{array}$ & \multicolumn{2}{|c}{ Accident Rate } \\
\cline { 4 - 4 } & Underground & Surface \\
\hline Shaft & Up to 99 thous. tons & 132 & 53 \\
& 100 to 199 thous. tons & 144 & 54 \\
& 200 to 349 thous. tons & 152 & 56 \\
& 350 to 699 thous. tons & 149 & 54 \\
& 700 thous. tons and over & 155 & 50 \\
\hline Drift & Up to 99 thous. tons & 113 & 60 \\
& 100 thous. tons and over & 130 & 51 \\
\hline
\end{tabular}

Miscellaneous Factors.-Data C were used to examine the suggestion that high surface accident rates are found where there are high underground rates and similarly that low surface and underground rates occur together. For this purpose the collieries were grouped according to whether their casualty rates were low, medium, or high. Table 8 shows the number of collieries which fall into each of the nine possible combinations of the groups of surface and underground rates. Shaft-raising collieries and drifts are considered separately.

Of the 163 shaft-raising collieries with a low underground accident rate, $97(60 \%)$ also had a low surface rate. Similarly, 126 collieries $(56 \%)$ of the 227 collieries with a high underground rate, also had a high surface rate. The pattern for drifts was similar.

It is therefore concluded that, over the country as a whole, there is a strong tendency for high accident rates to occur simultaneously on the surface and underground. Taking the divisions separately, the result was found to be true for shafts in five out of eight divisions and for drifts in all three divisions where they exist in substantial numbers. There is a strong tendency for all collieries with high underground accident rates to have high surface rates.

It was similarly found that collieries with a high underground accident rate in 1953 also tended to have a high rate in 1954. 
Negative Results.-For data A, we attempted to study the effects of environment and of changes in mechanization, the times at which accidents occur, the effect of management, and accident experience near holidays. For the 14 collieries covered by data $B$ a variety of descriptive information was taken from the colliery profile. This information included: Output of pit, productivity, depth of shafts, length of underground roadways, methods of mining, methods of underground transport, extent of mechanization, thickness of seams, extent to which shotfiring was employed, attendance, and supervision ratio.

Negative results were obtained in all these studies, probably because of the inadequacy of the data when considered from the particular point of view of this research rather than because the factors under examination were not important.

\section{Conclusions}

Although there was a vast quantity of data to be examined their quality was not high. Thus the research was basically a salvage operation-an attempt to obtain as much as possible from material collected for other purposes-and hence inevitably inadequate when considered from the point of view of research. In consequence, many of the results obtained either were negative or could be explained in terms of differences in habits, standards, and reliability of reporting.

It was noticeable, however, that where positive results did emerge from the study of data $A$, they were in general closely confirmed by the study of data B which was completely independent.

That we were unable to obtain many positive results is not surprising, but serves to emphasize that quantity is no substitute for quality. However, this is clearly not always appreciated as the statistician is often approached with the statement: "I have so much material it must be useful."

We conclude that there is a need for a study of the method of recording accidents at collieries to determine whether the recording which is necessary as a routine can be adapted to provide material for research purposes. As the recording of statutorily reportable casualties is reasonably reliable, statistical examination of the records of such accidents should be profitable. These studies are in fact being sponsored by the Medical Service of the National Coal Board, and special report forms were introduced for reportable accidents occurring in 1957. The Medical Service also sponsored a project being carried out by the Department of Experimental Psychology of the University of London. Here detailed reports were collected in a group of collieries for every reported casualty over a period of a year. This should also cast some light on the methods of recording, and will, of course, be complementary to the study of reportable accidents.

\section{Summary}

This report describes the results of work on three bodies of data, relating to accidents at collieries. The data were:

A: Basic data relating to each compensable casualty occurring at each of the 900 odd collieries in Great Britain during the five years 1945 to 1949.

B: More detailed data relating to each compensable casualty occurring at 14 particular collieries in the year 1953 .

C: Compensable casualty rates and background information for each of the 900 odd collieries for 1953 and 1954.

From an examination of published figures it appears that, although the rates of fatal and "reportable" casualties probably reflect the degree of safety enjoyed by collieries, the rates of compensable casualties do not. Data $A, B$, and $C$ all concern compensable casualties, and we have found in these data a substantial body of evidence that there are marked differences in habits of reporting and standards of recording. There were, therefore,

TABLE 8

NUMBERS OF COLLIERIES GROUPED BY UNDERGROUND AND SURFACE ACCIDENTS RATES: DATA C

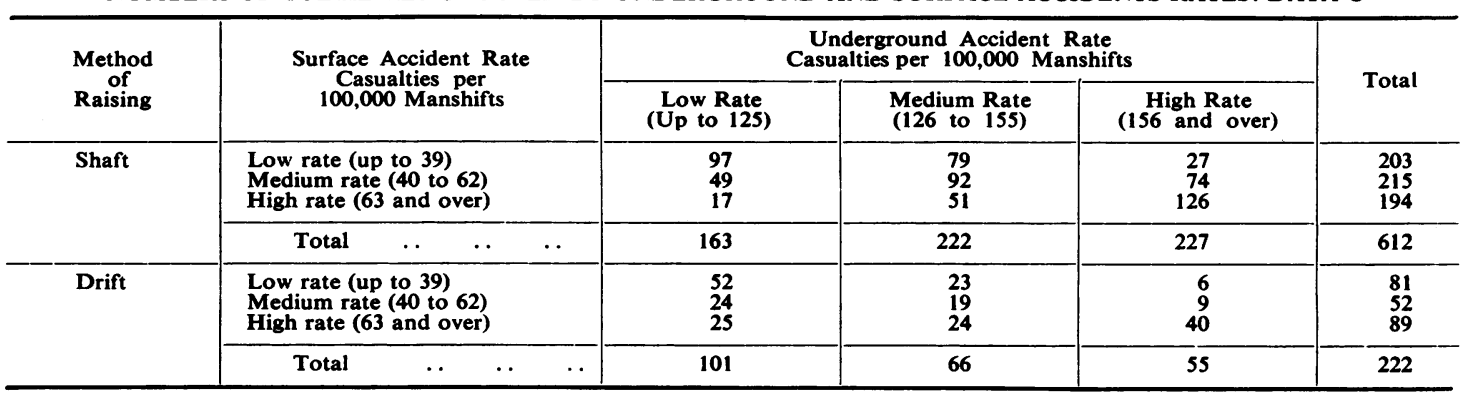


few positive results but those which were obtained with data $\mathbf{A}$ and $B$ were in close agreement.

Casualty rates were found to decrease with age, but this effect was mainly for the less serious injuries. In other words, the incidence of serious injuries did not depend on age, but younger men had more of the milder type of injury than their elders. After an injury, men over 50 were off work for rather longer than men of 21 to 50 . When men under 21 suffered serious injury they took as long to return to work as men over 50 , that is, much longer than their immediate elders in the 21 to 30 group.

It was found that casualty rates were always highest among coalface workers, with rates for workers elsewhere underground next, and surface workers' rates lowest. On the other hand, coalface workers had the shortest absences, because they had a high proportion of slight injuries which led to short absences. This high proportion of slight injuries, and the short absences resulting from them, tended to obscure the important finding that coalface workers also had about twice as many serious injuries as other workers. Apparent differences in lengths of absence between workers in the different places could be fully accounted for in terms of age and nature of injury. No particular occupational groups within the main places of work seemed to be substantially different in their accident experience.

There was no clear indication that underground accident rates increased with the size of colliery, but it was found that drifts, which were predominantly small, had lower accident rates than collieries of a similar size raising by shaft.

A strong tendency was found for collieries with high underground accident rates to have high surface rates, and vice versa. Similarly, the accident rate in a colliery appeared to be relatively stable from one year to another.

Studies of other factors did not lead to positive conclusions, probably on account of the inadequacy of the data.

We wish to acknowledge the help of all those concerned in this investigation, and in particular of Dr. J. M. Rogan, Chief Medical Officer, and Mr. R. F. George, Chief Statistician, of the National Coal Board.

The views expressed in this paper are our own and not necessarily those of the Board.

\section{REFERENCES}

Acton Society Trust (1953). Size and Morale. London. Liddell, F. D. K. (1955). J. roy. Stat. Soc. A., 118, 405. H.M.S.O., Ministry of Pow

Paterson, T. T. (1956). Operat. Res. Quart., 7, 155. 